\title{
Functional orthopedic appliance for vertical dimension increase and mandibular deprogramming ORLANDO SANTIAGO SYSTEM 1 - OSS1. Indications and laboratorial manufacturing
}

\author{
Orlando Santiago Júnior ${ }^{1}$, Mario Vedovello Filho², Marcus Vinicius Lucas Ferreira ${ }^{3}$, \\ Rudolf Huebner ${ }^{4}$ \\ ${ }^{1,4}$ Department of Mechanical Engineering, Universidade Federal de Minas Gerais, \\ Belo Horizonte, MG, Brazil \\ ${ }^{3}$ Department of Restorative Dentistry, Universidade Federal de Minas Gerais, Belo Horizonte, MG, Brazil \\ ${ }^{1}$ Dental School, Faculdade Arnaldo Jansen, Belo Horizonte, MG, Brazil \\ ${ }^{1}$ Dental School, Unicentro Promove, Belo Horizonte, MG, Brazil \\ ${ }^{2}$ Fundação Herminio Ometto - UNIARARAS, Araras, SP, Brazil \\ ${ }^{1}$ Corresponding author \\ E-mail: ${ }^{1}$ osjofm@gmail.com, ${ }^{2}$ mario@vedovelloeassociados.com.br, ${ }^{3}$ mv.mac@icloud.com, \\ ${ }^{4}$ rudolf@demec.ufmg.br
}

Received 27 May 2021; received in revised form 10 June 2021; accepted 17 June 2021 DOI https://doi.org/10.21595/jfocg.2021.22079

Check for updates

Copyright (C) 2021 Orlando Santiago Júnior, et al. This is an open access article distributed under the Creative Commons Attribution License, which permits unrestricted use, distribution, and reproduction in any medium, provided the original work is properly cited.

\begin{abstract}
Jaw Functional Orthopedics has efficient tools for treatment of deep bite, but, once they are bioplastic functional appliances, they have a considerable amount of acrylic resulting in volume that interferes with the individual phonetics. Planas had already described a Equiplan attached to a pipe to facilitate the use by the patient. Based on those ideas and in a attempt to improve use conditions of the functional orthopedic appliance, this paper presents the step by step of the manufacturing of an appliance with an Equiplan, used as background activity, or a main appliance, able to increase vertical dimension; used as contention in deep bite treatment; and in individuals with significant occlusal plane alterations, used as a mandibular deprogrammer. The appliance, when properly prescript, has a clinical conduction more efficient than occlusal splints because it does not require adjustment in every session. Its construction do not require articulated casts and can be done in less time in the laboratory.
\end{abstract}

Keywords: jaw functional orthopedics, jaw functional appliance construction, deep bite treatment, occlusal vertical dimension, tmd treatment.

\section{Introduction}

Mandibular deprograming is used in several areas of dentistry such as prosthesis, orthodontics, occlusion and treatment of temporomandibular disorders (TMD) [1] and is indicated for diagnosis [2] protection of the stomatognathic system (SS) against traumatic loads [3] and for treatment [4].

Despite being a subject still controversial the relationship between occlusion and TMD, some occlusal plane alterations are predisposing factors of TMD [5]. They are: Overbite greater than the $5 \mathrm{~mm}$; anterior open bite; the difference between centric relation and centric occlusion greater than $2 \mathrm{~mm}$; unilateral posterior cross-bite and loss of more than 6 posterior teeth. Although most associations were considered secondary [5] the presence of these occlusal alterations in patients with TMD justifies the treatment of the occlusal plane alteration.

There are functional orthopedic devices described in the literature to increase vertical dimensions [6-8] for deep bite treatment, and devices that deprogram mandibular position used in diagnosis and/or treatment in the areas of Prosthesis, TMD and Orthodontics [3, 4, 9-14].

In cases of deep bite treatment, the size of the functional orthopedic appliance (FOA) compromises the individual's speech, making it difficult to use during the day, what affects treatment time and final result quality prognosis. In cases of deprogramming mandibular position, 
the contact of the metal of the equiplan with the lower incisors raises the vertical dimension and put inferior and superior posterior teeth apart and allow mandible positioning in the most atraumatic way. In addition to the Orlando Santiago System 1 (OSS1) can be used at any age, with deciduous, mixed or permanent dentitions.

\section{Clinical relevance}

The functional orthopedic appliance proposed here has as main characteristic the facilitation of use by the patient, what allows the patient to use it for more hours during the day, especially in individuals who have to make use of speech, without significant loss of treatment time and quality.

\subsection{OSS1 indications}

It can be used as daytime FOA for vertical dimension increase - used as BGA (Background Activity); mandibular posture programmer; cases with small overjet and great overbite; TMD in individuals with great occlusal plane alteration and deep bite; correction of occlusal plane; posterior cross-bite with deep bite; mandibular deviation; maxillary expansion; mandibular posture change (MPC) in retrorotation [8]; conquer of space for permanent teeth; contention after deep bite treatment; increase of vertical dimension for rehabilitation of the occlusal plane with loss of vertical dimension, allow bonding of brackets on lower incisors [15].

\subsection{OSS1 mechanism of action}

The eruptive movement of the posterior teeth is stimulated by the equiplan and has the mechanism of action described by the Planas' Law of vertical growth [7] When the lower incisors touch the equiplan the stimulus is transmitted to all the teeth of the hemi mandible to which this incisor belongs. Since the device has no acrylic on the occlusal surfaces, the posterior teeth have no occlusal contact, so alveolar bone growth occurs in an attempt to seek for this contact [7]. The touch of the lower lateral incisors in the equiplan cancels the stimulus of the central incisors and vice versa. As for the upper incisors, the eruption process does not occur because the contact between them and the lower incisors during mandibular movements inhibits the process $[7,8]$.

\subsection{OSS1 construction}

OSS1 consists of a device made of acrylic resin. It has a modified Planas' equiplan $[7,8]$ (Fig. 1) made of steel in 0.3 up to $0.5 \mathrm{~mm}$ thickness properly cut or manufactured by Trimas Materias Odontológicos (Barbacena, MG, Brazil).

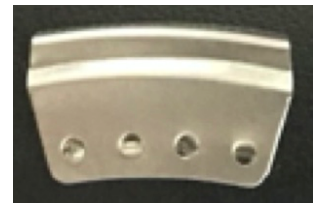

a)

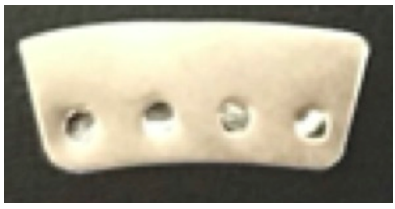

b)

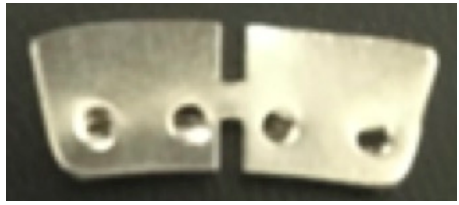

c)

Fig. 1. a) Original equiplan by planas, b) recorded equiplan for OSS1, c) equiplan for OSS1 semi-party (Trimas, Barbacena, MG, Brazil)

An expander screw of any brand on the market. Bilateral stabilizer clamps made of stainless steel wire $0.9 \mathrm{~mm}$ a pair in the anterior region and a pair in the posterior region in the more convenient tooth. These clamps can be asymmetric and serve only to enhance anchorage of the appliance to the upper dental arch, increasing the comfort. In OSS1 any accessories in the maxilla can be coupled (Fig. 2). 


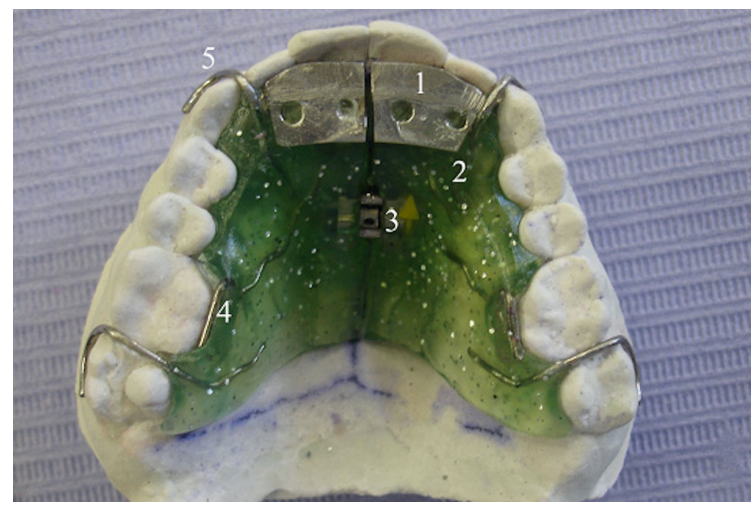

Fig. 2. Oclusal view of OSS1 in the cast. 1) equiplan; 2) acrylic; 3 expander screw;

4) resort in "S"; 5) retention clamp

The equiplan should be placed horizontally without any anteroposterior or lateral inclination (Fig. 3) to avoid MPC efficiency loss. The equiplan is positioned in the intercanine region, and its lateral borders are determined by the lower incisors diameter. All the lower incisors must be included in the equiplan length but the inferior canine cannot touch the equiplan.

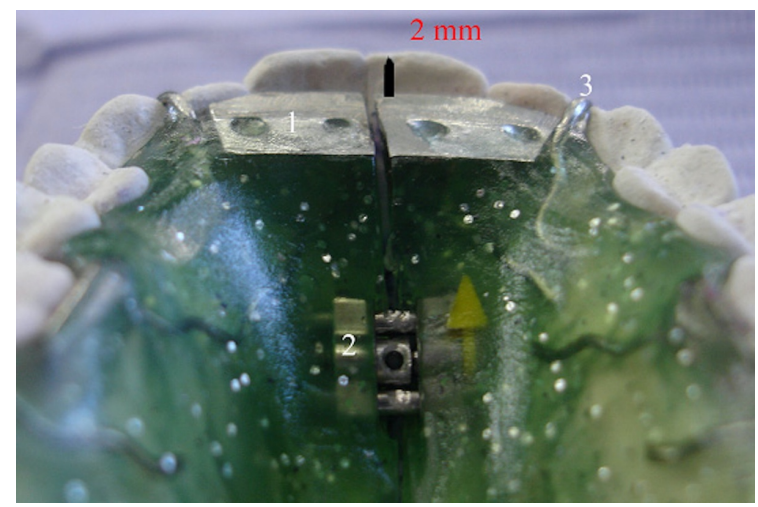

Fig. 3. Position of the equiplan. Horizontal and $2 \mathrm{~mm}$ above the incisal border of the incisors:

1) equiplan; 2) expander screw; 3) retention clamp

The equiplan cannot, in the anteroposterior view, exceed the second palatine wrinkle. The equiplan touches the palatine surface of upper incisors, not necessarily all of them or their entire length depending on their position and rotation. If the upper incisors are protruded the equiplan should not touch the palatine face the space between the tooth and the equiplan must be fulfilled with acrylic, facilitating its removal to allow incisor disinclination. It is not recommended to leave a gap between the equiplan and the upper incisors at the risk of the lower incisors fit into this gap and altering the MPC.

The equiplan should be placed two millimeters above the incisal of the upper incisors (Fig. 3) upside down so the retainers could attach it to the acrylic plate (Figs. 2, 3, 4). It should be cut with a mounted stone or a carburundum disc, according to the best convenience, to suit the boundaries described above. Once cut it is acrilized in the properly positioned. The equiplan can be cut in the maxillary middle line to allow maxillary expansion according to the convenience of each case and we recommend the semi-party esquiplan (Fig. 1(c)) to do so. 


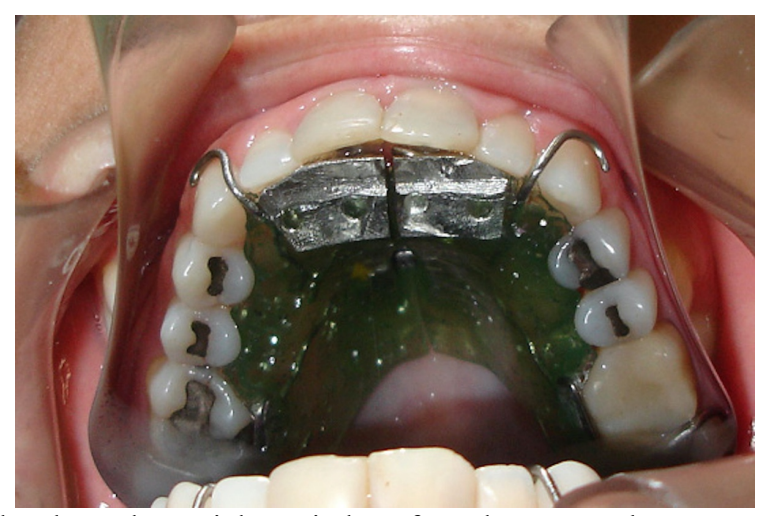

Fig. 4. OSS1 in mouth. Above the equiplan, Bimler's frontal resort can be seen. Resorts in "S" can be seen touching 16 and 26. Retention clamps placed on tooth 17 and 27

In Fig. 5(b, e, h) can be observed the MPC due to the OSS 1 in the casts with the vertical dimension raise. Comparing intra oral photos (Fig. 5(a, d, g)) without the appliance with introral photos with the OSS1 in mouth (Fig. 5(c, f, i)), the MPC in which the casts are mounted without articulator is exactly the same obtained in the mouth. For more information we recommend the reading of Simões [8] and Santiago Jr \& Santiago [16].

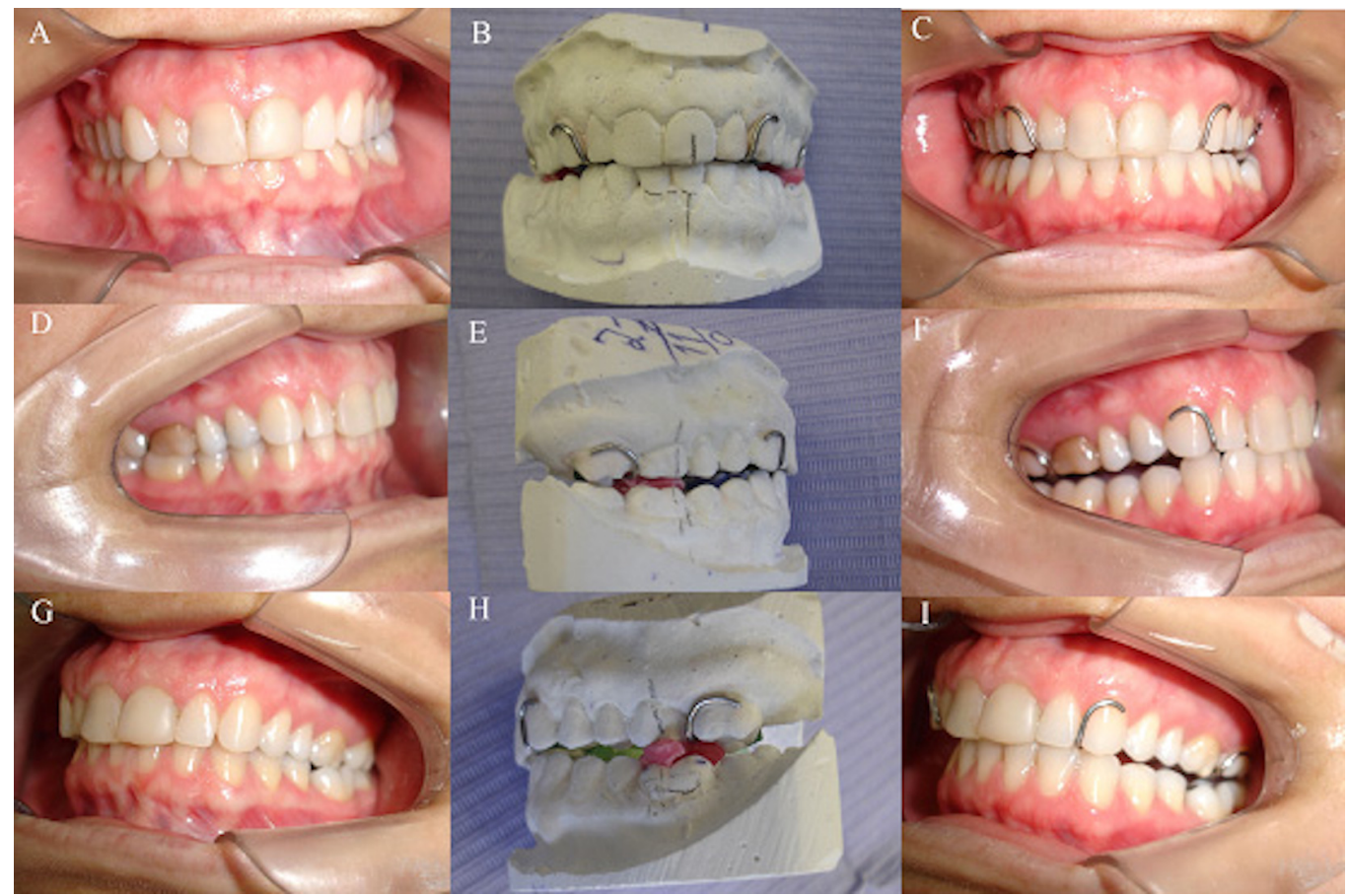

Fig. 5. MPC made by OSS1: a), d, g) centric occlusion; b) e), h) MPC in the casts and c), f), i) MPC with OSS1 in mouth

\section{Conclusions}

Since OSS1 is much smaller than other models of FOA, it facilitates daytime use for individuals who have to make use of the voice during the day. Because it is slightly less efficient than Bimler A and Planas Tracks (Compound Planas Indirect Tracks), it can be used by day while these appliances are used at night increasing treatment efficiency. In individuals who may use 
these devices during the day, the use of OSS1 is unnecessary. As for other devices with anterior acrylic plateau, such as those of Hawley and Sved [4], OSS1 is more efficient, since the equiplan is metallic, stimulates more the eruption of the posterior teeth than the contact with acrylic [7].

In relation to TMD treatment, in individuals where the occlusal plane cannot be altered, OSS1 is contraindicated. In individuals with deep bite and significant occlusal plane alterations the OSS1 appears to be more efficient, since this situation compromises treatment results with splints. This clinical finding must be properly studied in randomized clinical trials.

\section{References}

[1] M. M. Hamata, P. R. Zuim, A. R. Garcia, "Comparative evaluation of the efficacy of occlusal splints fabricated in centric relation or maximum intercuspation in temporomandibular disorders patients," Journal of Applied Oral Science, Vol. 17, No. 1, pp. 32-38, 2009, https://doi.org/10.1590/s167877572009000100007

[2] R. B. Morrish Jr., História e exame- "A estrutura para a descoberta", in Ciência e prática da oclusão, 1th Ed. São Paulo: Quintessence Ed., 2000, (in Portuguese).

[3] G. T. Clark, "Terapias com placas oclusais," in Fundamentos de oclusão, 2nd Ed. São Paulo: Quintessence Ed., 1991, (in Portuguese).

[4] S. Ramfjord, M. M. Ash, Oclusão, 3th Ed. São Paulo: Interamericana, pp. 271-294, 1984.

[5] J. P. Okeson, Dor Orofacial- guia de avaliação, diagnóstico e tratamento, 1th Ed. São Paulo: Quintessence Editora, 1998, (in Portuguese).

[6] H. P. Bimler, "The Bimler Appliance," in Removable orthodontic appliances, 1th Ed. Philadelphia: E. Saunders, pp. 337-350, 1977.

[7] P. Planas, Rehabilitación neuro-oclusal (RNO), 2th Ed. Barcelona: Masson Salvat Odontología, 1994, (in Spanish).

[8] W. A. Simões, Ortopedia Funcional Dos Maxilares Vista Através Da Reabilitação Neuro- Oclusal, 3ed. São Paulo: Artes Médicas, 2003, (in Portuguese).

[9] P. E. Dawson, Avaliação, Diagnóstico e tratamento dos problemas oclusais, 2nd ed. São Paulo: Artes Médicas, 1993, (in Portuguese).

[10] J. P. Okeson, Dores bucofaciais de Bell, 5th Ed. São Paulo: Quintessence Editora, 1998, (in Portuguese).

[11] R. N. Maciel, Oclusão e ATM - procedimentos clínicos, 1th Ed. São Paulo: Santos Livraria Editora, 1998, (in Portuguese).

[12] G. A. Zarb, G. E. Carlsson, J. D. Rugh, "Controle Clínico," in Disfunções da Articulação Temporomandibular e dos Músculos da Mastigação, 1th ed. São Paulo: Livraria e Editora Santos, pp. 529-548, 2000, (in Portuguese).

[13] F. G. P. Alencar Jr, A. B. Becker, "Placas Oclusais," in Oclusão, Dores Orofaciais e Cefaléia, 1th Ed. São Paulo: Santos Livraria e Editora, pp. 237-251, 2005, (in Portuguese).

[14] A.L. Valle, R.S. Silva, J.M. Scolaro, "Tratamento conservador das DTMs," in Noções e Conceitos Básicos em oclusão, Disfunção Temporomandibular e Dor Orofacial, 1th Ed. São Paulo: Santos Livraria e Editora, pp. 319-334, 2008, (in Portuguese).

[15] C. R. Douglas, "Fisiologia da postura mandibular," in Tratado de fisiologia aplicada à saúde, 5th Ed. São Paulo: Robe Ed., pp. 992-997, 2002, (in Portuguese).

[16] S. Asakawa, T. Al-Musaallam, C. S. Handelman, "Nonextraction treatment of a class II deepbite malocclusion with severe mandibular crowding: visualized treatment objectives for selecting treatment options," American Journal of Orthodontics and Dentofacial Orthopedics, Vol. 133, No. 2, pp. 308316, 2008, https://doi.org/10.1016/j.ajodo.2006.08.018

[17] K. Hering, S. Ruff, H. Pancherz, "Orthodontic treatment of openbite and deepbite high-angle malocclusions," The Angle Orthodontist, Vol. 69, No. 5, pp. 470-477, 1999, https://doi.org/10.1043/0003-3219(1999)069<0470:OTOOAD>2.3.CO;2

[18] K. L. Moore, T. V. N. Persaud, Embriologia Clinica, 5th. Ed. Rio de Janeiro: Guanabara Koogan, 1994, (in Portuguese).

[19] F. Mongini, ATM e Músculos craniocervicofaciais. Fisiopatologia e Tratamento, 1th Ed. São Paulo: Santos Livraria e Editora, 1998, (in Portuguese). 


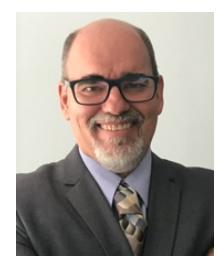

Orlando Santiago Júnior is a Ph.D. student in Mechanical Engineering (Department of Mechanical Engineering) Universidade Federal de Minas Gerais Belo Horizonte, MG, Brazil. Now he works at dental office and is Associate Professor at School of Dentistry at Faculdade Arnaldo Jansen, and School of Dentistry at Unicentro Promove, Belo Horizonte, MG, Brazil. His current research interest include jaw functional orthopedics, temporomandibular disorders, dental occlusion and bite force measurement, bioengineering, nanomaterials.

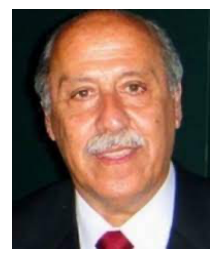

Mario Vedovello received Ph.D. in Orthodontics from Universidade Estadual de Campinas, Piracicaba, SP, Brazil. Works with cephalometric analisys, orthodontic biomechanics, and epidemiological investigations on malocclusion.

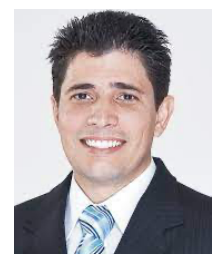

Marcus Vinicius Ferreira received Ph.D. in 2006, degree in Dentistry from Federal University of Minas Gerais, Belo Horizonte, Brazil, in 1997. Now he works at Federal University of Minas Gerais. His current research interests include lasertherapy, antimicrobial photodynamic therapy, prosthodontics, bioengineering, nanomaterials.

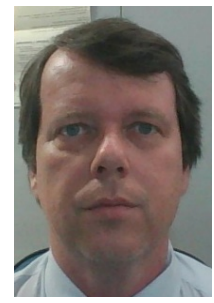

Rudolf Huebner received Ph.D. degree in Mechanical Engineering from Universidade Federal de Minas Gerais (UFMG), Belo Horizonte, Brazil, in 2003. Now he works at Mechanical Engineering Department of Universidade Federal de Minas Gerais. His current research interests include Mathematical Modelling and Numerical Simulation applied to Bioengineering (Cardiovascular Engineering, Dentistry, Physiotherapy). 